\title{
LIVING LABS IN A LEAN PERSPECTIVE
}

\author{
Joao Soliman-Junior ${ }^{1}$, Samira Awwal' ${ }^{2}$, Marcelle Engler Bridi ${ }^{3}$, Patricia \\ Tzortzopoulos $^{4}$, Ariovaldo Denis Granja ${ }^{5}$, Lauri Koskela ${ }^{6}$, and Danilo Gomes ${ }^{7}$
}

\begin{abstract}
Living Labs (LLs) consist of social and dynamic environments that enable end-users and stakeholders to collaborate towards an innovation. This paper presents the concept of LLs and analysis on how it can foster communication and collaboration from a lean perspective. Key concepts, such as co-creation, common ground, shared understanding and boundary objects are discussed in relation to LLs. The paper highlights the synergies between LLs and lean, including the focus on users' needs and values, the use of participatory approaches and early inclusion of stakeholders in the decision-making process, for example. There is however lack of clarity in the literature regarding the concept of LLs and, hence, there is a need for future empirical research to enable a better understanding of the synergies between Living Labs and lean.
\end{abstract}

\section{KEYWORDS}

Living labs, co-creation, common ground, shared understanding, boundary objects.

\section{INTRODUCTION}

Construction projects involve multiple stakeholders, including end-users and professionals, who have different backgrounds, experiences, knowledge, perspectives and interests. Such differences often lead to misalignments, inhibiting collaboration (Van Geenhuizen 2019), fostering a blame culture (Keeping 2000) and constraining shared knowledge (Pemsel and Widen 2011). Living Labs (LLs) are user-centred initiatives for the development of innovative solutions in real-life contexts through collaborative processes (Leminen and Westerlund 2017). LLs enable all stakeholders to be co-creators in innovation processes, rather than merely observers (Leminen et al. 2012). Users play an active role in the development of a product or artefact (Tang; Hämäläinen 2014), and their willingness to engage in LL activities impacts value creation. Therefore, the added

1 Research Assistant, Innovative Design Lab (IDL), University of Huddersfield, UK, j.solimanjunior@hud.ac.uk, orcid.org/0000-0002-8089-8628

$2 \mathrm{PhD}$ Student, Innovative Design Lab (IDL), University of Huddersfield, UK, samira.awwal@hud.ac.uk, orcid.org/0000-0001-7771-1511

3 PhD Student, Laboratory for Construction Management Research (LAGERCON), University of Campinas, Brazil, marcelle.bridi@gmail.com, orcid.org/0000-0003-4317-5938

4 Professor, Innovative Design Lab (IDL), University of Huddersfield, UK, p.tzortzopoulos@ hud.ac.uk, orcid.org/0000-0002-8740-6753

5 Associate Professor, Laboratory for Construction Management Research (LAGERCON), University of Campinas, Brazil, adgranja@m.unicamp.br, orcid.org/0000-0002-2964-5609

6 Professor, Innovative Design Lab (IDL), University of Huddersfield, UK, 1.koskela@hud.ac.uk, orcid.org/0000-0003-4449-2281

7 Senior Lecturer, Innovative Design Lab (IDL), University of Huddersfield, UK, d.gomes@ hud.ac.uk, orcid.org/0000-0002-1963-392X 
value of users' participation in LLs has societal and technological dimensions, such as users accessing products that meet their real needs, the development of creative skilled communities and fostering new employment opportunities (Paskaleva et al. 2015).

Participatory approaches to support design and construction have been already discussed by the lean community (e.g. Sfandyarifard and Tzortzopoulos 2011). Furthermore, Koskela et al. (2016) presented a review of concepts supporting communication and collaboration in construction projects from a lean perspective, including shared understanding and common ground. This paper draws upon the work of Koskela et al. (2016), aiming to conceptually analyse potential synergies between LLs and lean, based on these key concepts. The paper is part of a research project entitled User-Valued Innovations for Social Housing upgrading through Trans-Atlantic Living Labs (uVITAL). This project is being developed through a collaboration between UNICAMP (Brazil), TU Delft (Netherlands), UFZ Helmholtz Centre for Environmental Research (Germany) and The University of Huddersfield (UK). The aim of uVITAL is to advance on user-valued innovations for social housing upgrading through transatlantic Living Labs. This paper is structured as follows: after presenting Living Labs both conceptually and how cases have been reported in the literature, key collaboration and communication concepts are discussed as to how they relate to LLs. A discussion on the synergies between LLs and lean is presented, followed by conclusions and limitations to be addressed in future work.

\section{LIVING LABS}

The LL terminology was first introduced in the early 1990s (Nesti 2018), whereas the first largely acknowledged development is attributed to the 'PlaceLab' - an initiative from MIT's professor William Mitchell (Eriksson et al. 2005; Leminen et al. 2012). The initial focus of LLs was on emerging technologies in home-like environments (BergvallKåreborn et al. 2009; Tang and Hämäläinen 2014). Over time, they have been used in different domains, such as energy, mobility, healthcare, urban design and housing (ENoLL 2021), addressing complex social, economic, cultural and political challenges (Claude et al. 2017).

LLs are innovation-driven, whereas value is created by engaging with relevant stakeholders (Bergvall-Kåreborn et al. 2009). They are based on placing users and other value chain actors at the centre of the innovation process (Leminen 2015). This process enables collaboration between the people and organisations that are part of the development of an innovation or are affected by it, such as users, public and private partners, researchers, financial investors, regulators, policy makers, citizen groups, among others (Niitamo et al. 2006; van Geenhuizen 2019). The literature presents multiple definitions for LLs (Bergvall-Kåreborn et al. 2009; Steen and Van Bueren 2017), as highlighted in table 1.

The variety of definitions presented in table 1 indicates a lack of conceptual clarity on LLs, suggesting different ontological assumptions regarding their understanding. The focus on improving collaboration and participation to promote social innovation is key (Almirall and Wareham 2011). Because solutions are created and validated in multicontextual and real environments (Van Der Walt et al. 2009), LLs foster bottom-up communication and collaboration between stakeholders (Tang and Hämäläinen 2014), especially when it comes to achieving social transformation (Oliveira and Brito 2013).

LLs include user involvement as an intrinsic feature (Eriksson et al. 2005; Niitamo et al. 2006; Tang and Hämäläinen 2014; Leminen 2015). More specifically, they focus on 
identifying end users' needs and societal problems, hence solutions can be collectively designed, prototyped, validated and refined in real-life contexts (Westerlund and Leminen 2011 apud Nesti 2018). As such, they support stakeholders to fully address user's needs (Leminen 2015). This relies on end-users and stakeholders collaborating directly together in LL activities (van Geenhuizen 2019), as in design and prototyping workshops, project meetings and training sessions, playing a co-creation role (Tang and Hämäläinen 2014).

Table 1: Main Living Lab definitions in the existing literature

\begin{tabular}{|c|c|c|}
\hline Reference & Definition & Understanding \\
\hline $\begin{array}{l}\text { Eriksson et al. } \\
(2005 \text { p. 4) }\end{array}$ & $\begin{array}{l}\text { "A user-centric research methodology for sensing, } \\
\text { prototyping, validating and refining complex solutions } \\
\text { in multiple and evolving real-life contexts" }\end{array}$ & Method \\
\hline $\begin{array}{l}\text { Van Geenhuizen } \\
\text { (2019 p. 28) }\end{array}$ & $\begin{array}{l}\text { "Aside from innovation methodology, the term living } \\
\text { labs often also refers to the (temporary) organizational } \\
\text { structure in which the methodology is implemented" }\end{array}$ & $\begin{array}{l}\text { Method; } \\
\text { Environment }\end{array}$ \\
\hline $\begin{array}{l}\text { Ballon and } \\
\text { Schurmann. } \\
\text { (2015 p. 2) }\end{array}$ & $\begin{array}{l}\text { "An experimentation environment in which technology } \\
\text { is given shape in real-life contexts and in which (end) } \\
\text { users are considered co-producers" }\end{array}$ & Environment \\
\hline $\begin{array}{l}\text { Oliveira and Brito } \\
\text { (2013 p. 202) }\end{array}$ & $\begin{array}{l}\text { "Open ecosystems that engage and motivate } \\
\text { stakeholders into an innovation process, encourage } \\
\text { collaboration, facilitate and accelerate the creation and } \\
\text { sustainability of new markets and business models" }\end{array}$ & $\begin{array}{l}\text { Ecosystem; } \\
\text { Environment }\end{array}$ \\
\hline $\begin{array}{l}\text { Papadonikolaki; } \\
\text { van Oel; Kagioglou } \\
\text { (2019 p. 385) }\end{array}$ & $\begin{array}{l}\text { "User-centred sessions focusing on co-creating } \\
\text { meaning with the participants, exploring scenarios and } \\
\text { evaluating propositions" }\end{array}$ & Sessions \\
\hline
\end{tabular}

\section{Living Lab in Practice}

Even though LLs have common conceptual elements, there are multiple forms of implementation observed in practice (ENoLL 2021). Existing literature is fragmented, with few comprehensive descriptions of LL activities. Reported LL cases usually start from (i) a problem, by getting people together to initiate an endeavour and come up with ideas for a solution; or (ii) with an idea, when partners set up a lab for experimentation, further connecting the idea to a relevant problem (Steen and van Bueren 2017). Examples of LL cases are presented in tables 2 and 3.

LLs are reported as a linear or non-linear process, using standardised or customised tools (Leminen et al. 2012). Tang and Hämäläinen (2014) synthesised LL processes in a four-stage iterative model: (1) requirements; (2) co-design; (3) prototyping; and (4) test and tracking. The model placed end-users at the centre of the process and included an output stage (5) commercialisation. The model proposed by Steen and Van Bueren (2017) focuses on the use of LLs at an urban scale and included six cyclical and iterative stages: (1) plan development; (2) co-creative design; (3) implementation; (4) evaluation; (5) refinement; and (6) dissemination, preceded by (0) initiation and closed with (7) replication. This model provides a generic process in which participants allocate themselves in the LL, supporting activities in a constructive, proactive and efficient way.

As discussed, there is no standard LL process reported by existing research, despite the similarities between models. This is also observed regarding the participants involved, and resources used in LLs, which vary signif|icantly according to their specific contexts and objectives (as seen in tables 2 and 3). This can be due to of the lack of conceptual 
clarity, as identified in table 1 . As a consequence, reported LL cases are diverse and fragmented, presented through different formats and detail levels.

Table 2: Descriptive examples of Living Lab cases

Exhibit 1: Nesti (2018)

Exhibit 2: Johansson and Snis (2011)

Nesti (2018) describes a housing innovation lab that was created in 2015 to provide affordable housing in Boston. The project collaborated with housing experts, community organisations and residents to develop solutions, considering the high living costs in the local area. The lab started with pilot projects relating to density, compact living and alternative housing models. It was followed by exploration, experimentation and evaluation. Initially, housing problems and users' needs were identified by interviewing key residents; then, users' needs were analysed and led to alternative solutions. Through a testing option with residents, feedback was collected, supporting the proposition of recommendations. For example, the "Urban Housing Unit Roadshow" consisted of a compact apartment on wheels. It was placed in different areas of the city. Residents were asked to experiment the apartment and give feedback. The information further helped to define needs and recommendations associated to compact living.

Johansson and Snis (2011) reported empirical results from "The Find Project" developed by the Halmstad Living Lab in Sweden. The purpose was to customise a sender and receiver device to find missing objects and people, fitted to the needs of elderly and demented users. Co-creation activities involved researchers, developers and target users relatives. The project was held in an apartment equipped with tools and artefacts to serve as a real-life context test laboratory. It enabled developers to present statements and questions on workshops to compare the users' needs with the device prototypes. It also consisted of building and designing the prototypes. Participants were asked to be creative and propose design ideas for both receiver and sender devices using sketches or models (e.g. jewellery piece). The activity also included presenting and discussing results with the group.

Table 3: Examples of Living Lab cases

\begin{tabular}{|c|c|c|c|}
\hline Reference & Living Lab Objective & Participants & $\begin{array}{c}\text { Examples of resources and } \\
\text { activities }\end{array}$ \\
\hline $\begin{array}{l}\text { Claude et } \\
\text { al. (2017) }\end{array}$ & $\begin{array}{l}\text { Validate refurbishment } \\
\text { techniques based on } \\
\text { ecological materials } \\
\text { through a scientific } \\
\text { experiment. Testing } \\
\text { materials in the } \\
\text { laboratory, but also } \\
\text { directly in a real context }\end{array}$ & $\begin{array}{l}\text { Craftsmen, students, } \\
\text { local authorities, } \\
\text { material producers }\end{array}$ & $\begin{array}{l}\text { Workshops, lab simulations, } \\
\text { in-situ sensor monitoring, } \\
\text { hardware infrastructure for } \\
\text { monitoring empty building } \\
\text { before and after }\end{array}$ \\
\hline $\begin{array}{l}\text { Lockton et } \\
\text { al. } 2013\end{array}$ & $\begin{array}{l}\text { Developing devices that } \\
\text { help to save energy and } \\
\text { enhance comfort in } \\
\text { terms of heating }\end{array}$ & $\begin{array}{c}\text { City institute and } \\
\text { partner university, } \\
\text { advisory board, local } \\
\text { and regional housing } \\
\text { companies }\end{array}$ & $\begin{array}{l}\text { Visits and interviews, energy } \\
\text { displays, Home Energy } \\
\text { Hackday, co-creation } \\
\text { workshops, monitoring toolkit } \\
\text { (tablet for self-reporting), } \\
\text { Prototype testing }\end{array}$ \\
\hline $\begin{array}{l}\text { Boess et } \\
\text { al. (2018) }\end{array}$ & $\begin{array}{c}\text { Deliver a scalable zero- } \\
\text { energy renovation of } \\
\text { outdated multistorey } \\
\text { housing }\end{array}$ & $\begin{array}{l}\text { Housing association, } \\
\text { construction } \\
\text { company, } \\
\text { researchers, resident } \\
\text { representatives }\end{array}$ & $\begin{array}{c}\text { Invitation letter, discussion } \\
\text { sessions, A2 sheets (design), } \\
\text { physical components } \\
\text { (renovation samples), } \\
\text { informal chats, reflection } \\
\text { booklets }\end{array}$ \\
\hline
\end{tabular}




\section{KEY CONCEPTS: RELATIONSHIP TO LIVING LABS}

The following discussion explores communication and collaboration, aiming to understand and identify potential synergies between LLs and lean. This includes four key concepts and their relationship to LLs i.e., co-creation, common ground, shared understanding and boundary objects. These concepts have been discussed as preconditions to communication and collaboration in construction projects (Koskela et al. 2016; Gomes et al. 2016) and can help better understanding LLs under a lean perspective.

\section{Co-Creation}

Co-creation can be understood as an act of collective creativity or "creativity that is shared by two or more people" (Sanders and Stappers 2008 p. 6). The referred authors discuss co-creation in the context of participatory design and understand this as a broad definition. Co-creation is intrinsic to LLs (Nesti 2017) and when practised at early stages has a positive impact on its outcomes (Sanders and Stappers 2008). The importance of co-creation is also reinforced in LL definitions, e.g. "Living labs are user-centred sessions focusing on co-creating meaning with the participants, exploring scenarios and evaluating propositions" (Papadonikolaki et al. 2019, p. 385).

Although collaboration is fundamental to achieve co-creation, endeavours might differ on how stakeholders collaborate and co-create artefacts (Schuurman et al. 2013). Depending on how a LL evolves and stakeholders develop relationships, more intensive ideation and co-creation activities can be achieved (Leminen et al. 2019). This reflects the nature of collaborative design, which is based on collective creative processes and multidisciplinary project actors deliberately co-creating design solutions over time (Papadonikolaki et al. 2019). It also suggests that co-creation depends on common ground and shared understanding, whereas a LL environment helps achieving them in practice.

\section{COMMON GRound}

Common ground can be defined as a presumption of awareness (Clark 1996), being achieved when people share the same knowledge and beliefs (Holtgraves 2002; Stalnaker 2002). However, Holtgraves (2002) argues that common ground exists regardless of people's awareness of it. Koskela et al. (2016) explain common ground as a concept derived from classical rhetoric, which plays a vital role in effective communication and collaboration (Geurts 2018). Common ground is the primary basis for successful communication and it is the starting point to persuade the speaker and the audience to understand mutual grounds (Kecskes and Zhang 2009). This highlights that common ground can act as a starting point towards mutual understanding between the interlocutors and stakeholders involved in a process (Geurts 2018; Feurstein et al. 2008).

According to Feurstein et al. (2008), stakeholders should be directly connected to mitigate risks in design. In a LL, all relevant stakeholders are identified and engaged at the start of the process (Van Der Walt et al. 2009), and communication strategies to support initial interactions are proposed to overcome likely conflicts and boundaries (Pemsel and Widén 2011). As the common ground is the primary basis for successful communication (Geurts 2018; Kecskes and Zhang 2009), it has a direct impact on LLs not only from a process perspective but also considering their social character.

\section{SHARED UNDERSTANDING}

Shared understanding can be defined as "the ability of multiple agents to exploit common bodies of causal knowledge for the purpose of accomplishing common (shared) goals" 
(Smart et al. 2009, p. 2). Gomes et al. (2016, p. 70) further state that shared understanding is an "ability to be collectively developed", being dynamic and influenced by the context of the project and its social aspects. The same authors argue that this process involves two abilities: one of collective action for sense-making; and the other of collective coordination of interdependent perceptions between team members.

Valkenburg (1998) states that the absence of shared understanding creates miscommunication, potentially delaying the design process. As LLs are based on collaborative efforts (Almirall and Wareham 2011), achieving shared understanding is key to enabling LLs through a social, context-based and collective effort.

\section{BOUNDARY OBJECTS}

Star (1989) describes Boundary Objects (BOs) as an analytical concept for objects that can coexist between different social worlds and satisfy individuals' information needs. Those objects can be abstract or physical artefacts, and they incorporate multiple meanings, while sharing a common structure which allows interaction by maintaining coherence across different knowledge areas (Star and Griesemer 1989). BOs can be artefacts such as timelines, drawings, 3D models, among others (Koskela et al. 2016). Generally, BOs are seen as tools that create common understanding between participants allowing collaboration even with a lack of consensus (Kjølle and Blakstad 2014).

LLs involve a network of stakeholders requiring mediating activities and translating different interests and understandings. This leads to the construction of BOs that are both meaningful and acceptable between participants (Paskaleva et al 2015). Existing research on LLs addressed BOs in multiple forms: (a) as a way to transpass communication boundaries (Paskaleva et al. 2015); (b) as the materialisation of ideas and concepts during co-creation (Johansson and Snis 2011) and (c) as both physical and imaginary artefacts that connect stakeholders coordinate participants (Engels and Münch 2015).

\section{DISCUSSION: LIVING LABS AS A LEAN APPROACH}

The previous discussion demonstrates that LL's outcomes are impacted by how effectively stakeholders communicate, collaborate and co-create artefacts while considering end-users' needs. The LL process, therefore, depends on many of the preconditions for communication and collaboration discussed by the lean community, such as those explored by Koskela et al. (2016). In a LL context, participatory approaches support the co-creation of not only innovative artefacts but also of meaning between different stakeholders (Papadonikolaki et al. 2019). This highlights the role of LLs to support shared understanding. Furthermore, the synthesis presented in this paper demonstrates that LLs do not necessarily refer to a 'place' or a 'specific setting', but to a social, context-dependent and dynamic environment that enables stakeholders to better communicate and collaborate towards a user-driven innovation.

Nevertheless, a starting point for such understanding can be associated with the steering user-driven approach in Living Labs. In practice, it has been recognized that collaborative design interactions will lead to compromises, where different needs and interests are negotiated and balanced across project stakeholders influenced by aspects of power and interest. Because end-users and other stakeholders are fundamental actors engaged in the Living Lab from the start, their needs should be key project drivers. The early involvement of stakeholders and team initiation create opportunities for the collective exchange of opinions, ideas and analysis of trade-offs, supporting collaborative decision-making and facilitating the elicitation of potential misalignments. This 
integration of project stakeholders is also an essential element of Integrated Project Delivery (IPD) projects. In this context, LLs could complement IPD projects in a way as to achieve even more benefits, acknowledging the main focus of LLs on their end-users.

Multiple participatory approaches reported in lean research relate to prototyping, mock-ups, focus groups and co-design workshops. As observed in table 3, they are also part of many LLs, usually highlighted as BOs that support the development of common ground and shared understanding. Additionally, because of the way LLs enable iterative processes, there is an opportunity for accelerated feedback loops, suggesting a synergy between lean and Living Labs. A summary of the potential synergies between LLs and lean is presented in table 4, also highlighting their related lean principles (Koskela 1992).

Table 4: Key synergies between Living Labs and lean

\begin{tabular}{|c|c|c|}
\hline Synergy & Description from LLs & $\begin{array}{l}\text { Lean } \\
\text { Principles }\end{array}$ \\
\hline $\begin{array}{l}\text { Focus on } \\
\text { users' needs } \\
\text { and values }\end{array}$ & $\begin{array}{l}\text { LLs are user-driven initiatives aiming to address their specific } \\
\text { needs and values. There is a clear link between LLs and } \\
\text { value generation }\end{array}$ & $\begin{array}{l}\text { Increase } \\
\text { value }\end{array}$ \\
\hline $\begin{array}{l}\text { Participatory } \\
\text { approach; }\end{array}$ & $\begin{array}{l}\text { LLs are based on participatory approaches through co- } \\
\text { creation. These include the development of both physical } \\
\text { artefacts such as prototypes, often used as BOs, but also } \\
\text { abstract artefacts to support collective sense-making. }\end{array}$ & $\begin{array}{l}\text { Increase } \\
\text { value }\end{array}$ \\
\hline $\begin{array}{l}\text { Early } \\
\text { stakeholder } \\
\text { involvement; } \\
\text { Team forming } \\
\text { and initiation }\end{array}$ & $\begin{array}{l}\text { In LLs, stakeholders are identified and engaged from the } \\
\text { beginning of the process, whereas communication strategies } \\
\text { support initial interactions to overcome potential conflicts and } \\
\text { boundaries. }\end{array}$ & $\begin{array}{l}\text { Increase } \\
\text { value; } \\
\text { Increase } \\
\text { transparency }\end{array}$ \\
\hline $\begin{array}{l}\text { Environment } \\
\text { that supports } \\
\text { collaboration, } \\
\text { transparency }\end{array}$ & $\begin{array}{l}\text { LLs provide an experimentation environment in real-life } \\
\text { context, supporting the development of common ground and } \\
\text { shared understanding through increased transparency and } \\
\text { collaboration between stakeholders (as per tables } 2 \text { and } 3 \text { ). }\end{array}$ & $\begin{array}{l}\text { Increase } \\
\text { transparency }\end{array}$ \\
\hline $\begin{array}{l}\text { Iterative } \\
\text { process }\end{array}$ & $\begin{array}{l}\text { LL cases are usually reported as iterative processes with } \\
\text { multiple evaluation points and feedback loops, suggesting a } \\
\text { link to continuous improvement both in the process, but also } \\
\text { in the innovation under development. }\end{array}$ & $\begin{array}{l}\text { Continuous } \\
\text { improvement }\end{array}$ \\
\hline $\begin{array}{l}\text { Feedback } \\
\text { loops }\end{array}$ & $\begin{array}{l}\text { The iterative process in LLs enables accelerated feedback } \\
\text { loops (as evidenced by, contributing to the reduction of cycle } \\
\text { times. }\end{array}$ & $\begin{array}{l}\text { Reduce } \\
\text { cycle times }\end{array}$ \\
\hline
\end{tabular}

Table 4 is limited to the conceptual analysis presented in the paper. It needs to be further supported with empirical data, given the real-life character of LLs and due to the lack of clarity in existing research related to concepts, processes and activities associated with LLs, as presented in Tables 1 and 2. The contexts in which LLs have been used and the scale of the projects reported in cases are varied. Applications range from urban to housing scales, and from major sustainable programmes to the development of specific mobile devices. Despite the plethora of uses reported in existing research, LLs have been typically applied to improve value generation through collective sense-making. Interestingly, many of the situations in which participatory approaches have been used and reported by lean research relate to healthcare projects (e.g., Sfandyarifard and Tzortzopoulos 2011), whereas these have not been explored with similar emphasis in LLs. 


\section{CONCLUSIONS}

The theoretical discussion here presented show that LLs should be understood not as a 'place' where stakeholders meet and co-create solutions, but as a social, contextdependent and dynamic environment that enables end-users and stakeholders to better communicate and collaborate towards an innovation. Also, lean construction practices as described in the previous section could be further enhanced by using a LL approach. This paper demonstrates that key lean concepts and practices are also part of LLs, highlighting potential synergies between LLs and lean, suggesting that lean projects could benefit from LLs and vice-versa. Whereas the impact of LLs in lean tends to be as an approach to improve construction projects further; the use of lean can help LLs in a greater and broader sense. There is an opportunity to incorporate multiple lean tools and approaches related to stakeholders and value management, collaboration and continuous improvement, which have not been explored in the LL context yet.

The analysis here described relates to early research findings and is solely based on literature review, meaning that no empirical data has been collected yet. Furthermore, the lack of conceptual clarity on LLs suggests that the initial concept proposed in the 1990s might have diverged over time and LLs have been understood differently from an ontological perspective in practical implementations. Nevertheless, there is still a conceptual gap associated with LLs' definition, to be addressed in future research.

Even though the potential synergy between LLs and lean (table 4) suggests some commonalities emerging from reported LL approaches, activities and project contexts, further investigation in practice is needed. This represents a limitation of the paper due to the convoluted theoretical background associated with LLs. This also means that framing LLs as a lean approach, and investigating the benefits and limitations of such practical interplay demands further empirical and theoretical investigation.

\section{ACKNOWLEDGEMENTS}

This paper reports on partial results from the uVITAL project, funded by the TransAtlantic Platform for Social Sciences and Humanities (ES/T015160/1). Authors would also like to thank FAPESP, CAPES, CNPq and IDL for their financial support.

\section{REFERENCES}

Almirall, E., and Wareham, J. (2011). "Living Labs: arbiters of mid- and ground-level innovation." Technology Analysis \& Strategic Management, 23:1, 87-102.

Ballon, P., Van Hoed, M., and Schuurman, D. (2018). "The effectiveness of involving users in digital innovation: Measuring the impact of living labs." Telematics and Informatics, 35(5), 1201-1214.

Bergvall-Kåreborn, B. H. M. S. A., Hoist, M., and Stahlbrost, A. (2009). "Concept design with a living lab approach." 42nd Hawaii Int. Conf. on Syst. Sciences (pp. 1-10). IEEE.

Boess, S., Silvester, S., De Wal, E., and De Wal, O. (2018). "Acting from a participatory attitude in a networked collaboration." ACM Int. Conf. Proceeding Series, 2, 1-6.

Claude, S., Ginestet, S., Bonhomme, M., Moulène, N., and Escadeillas, G. (2017). "The Living Lab methodology for complex environments" Energy Research \& Social Science, 32, 121-130.

Clark, H. (1996). “Using language.” Cambridge: Cambridge University Press.

ENoLL. (2021). “About us” Enoll, https://enoll.org/about-us/ (Jan. 27, 2021). 
Engels, F., and Münch, A. V. (2015). "The micro smart grid as a materialised imaginary within the German energy transition." Energy Research \& Social Science, 9, 35-42.

Eriksson, M., Niitamo, V. P., \& Kulkki, S. (2005). "State-of-the-art in utilizing Living Labs approach to user-centric ICT innovation", Lulea University of Technology

Feurstein, K., Hesmer, A., Hribernik, K. A., Thoben, K. D., \& Schumacher, J. (2008). Living Labs: a new development strategy. In: European Living Labs-a new approach for human centric regional innovation, Verlag Berlin, 2008, pp. 1-14.

Geurts, B.(2018).“Convention and common ground."Mind \& Language,33(2),115-129.

Gomes, D., Tzortzopoulos, P., and Kagioglou, M. (2016). "Collaboration Through Shared Understanding in Early Design Stage.” In: Proc. 24th Ann. Conf. of the Int'l. Group for Lean Construction, Boston, MA, USA, sect.7 pp. 63-72.

Holtgraves, T. M. (2002). "Language as Social Action: Social Psychology and Language Use." Mahwah NJ: Lawrence Erlbaum.

Johansson, L. O. and Snis, U. S. (2011). "The dynamics of interaction: exploring a living lab innovation process from a community of practice perspective." In: Proceedings of Pacific Asia Conference on Information Systems (PACIS).

Kecskes, I. and Zhang, F. (2009). "Activating, seeking, and creating common ground: A socio-cognitive approach." Pragmatics \& Cognition, 17(2), 331-355.

Keeping, M. (2000). "What about demand? Do investors want 'green buildings'?" In: Sustainable Building. Int'l. Conf. Sustainable Building. The Netherlands.

Kjølle, K. H., and Blakstad, S. H. (2014).“Architects and end users:Boundary objects in participatory briefing and design."Nordic Journal of Architectural Research, 1, 20.

Koskela, L. (1992). "Application of the new production philosophy to construction" (Vol. 72). Stanford: Stanford University.

Koskela, L., Pikas, E., Gomes, D., Biotto, C., Talebi, S., Rahim, N., and Tzortzopoulos, P. (2016). "Towards shared understanding on common ground, boundary objects and other related concepts." In: Proc. 24 ${ }^{\text {th }}$ Ann. Conf. of the Int'l. Group for Lean Construction, Boston, MA, USA, sect.1 pp. 63-72.

Leminen, S. (2015). “Q\&A. What Are Living Labs?" Technology Innovation Management Review, 5(9), 7.

Leminen, S., Nyström, A.-G., and Westerlund, M. (2019). "Change processes in open innovation networks - Exploring living labs.” Industrial Marketing Management.

Leminen, S., Westerlund, M., and Nyström, A.-G. (2012). "Living Labs as OpenInnovation Networks." Technology Innovation Management Review, 2(9): 6-11.

Lockton, D., Greene, C., Brass, C., and Gheerawo, R. (2013). "SusLabNWE : Integrating qualitative and quantitative data to understand people's everyday energy behavior." In: Behavior, Energy \& Climate Change 2013 conference.

Niitamo, V., Kulkki, S., Eriksson, M. and Hribernik, K. A. (2006). "State-of-the-art and good practice in the field of living labs." 2006 IEEE International Technology Management Conference (ICE), Milan, pp. 1-8.

Nesti, G. (2018). "Co-production for innovation: The urban living lab experience." Policy and Society, 37:3, 310-325.

Oliveira, Á., de, and Brito, D., A., de. (2013). "Living Labs: a experiência Portuguesa." CTS: Revista iberoamericana de ciencia, tecnología y sociedad, 8(23), 201-229.

Papadonikolaki, E., van Oel, C., and Kagioglou, M. (2019). "Organising and Managing boundaries: A structurational view of collaboration with Building Information Modelling (BIM)." International Journal of Project Management, 37(3), 378-394. 
Paskaleva, K., Cooper, I., Linde, P., Peterson, B., and Götz, C. (2015). "Stakeholder Engagement in the Smart City: Making Living Labs Work." In: Transforming City Governments for Successful Smart Cities (p. 115-145). Springer International.

Pemsel, S., and Widén, K. (2011). "Bridging boundaries between organizations in construction." Construction Management and Economics, 29(5), 495-506.

Sanders, E. B. N., and Stappers, P. J. (2008). "Co-creation and the new landscapes of design." Co-design, 4(1), 5-18.

Schuurman, D., Mahr, D., De Marez, L., and Ballon, P. (2013). "A fourfold typology of living labs: an empirical investigation amongst the ENoLL community." In: 2013 Int. Conf. on Engineering, Technology and Innovation (ICE) (pp. 1-11). IEEE.

Sfandyarifard, E. and Tzortzopoulos, P. (2011). "Supporting Value Generation in Children's Hospital Design Through Participatory Approaches" In: Rooke, J. \& Dave, B., 19th Ann. Conf. of the Int. Group for Lean Construction. Lima, Peru, 13-15 July.

Smart, P. R., Mott, D., Sycara, K., Braines, D., Strub, M., and Shadbolt, N. R. (2009). "Shared understanding within military coalitions: A definition and review of research challenges." Southampton.

Stalnaker, Robert C. (2002).“Common ground.”Linguistics and Philosophy 25: 701-21.

Star, S. L. (1989). "The Structure of Ill-Structured Solutions: Boundary Objects and Heterogeneous Distributed Problem Solving.” Distr. Artific. Int., 37-54.

Star, S. L., and Griesemer, J. R. (1989). "Institutional Ecology, 'Translations' and Boundary Objects: Amateurs and Professionals in Berkeley's Museum of Vertebrate Zoology, 1907-39." Social Studies of Science, 19(3), 387-420.

Steen, K., and Van Bueren, E. (2017). "Urban living labs. A living lab way of working." Amsterdam: Amsterdam Institute for Advanced Metropolitan Solutions.

Tang, T., and Hämäläinen, M. (2014). "Beyond Open Innovation: the Living Lab Way of ICT Innovation.” Interdisciplinary Studies Journal, 3(4), 15.

Valkenburg, R. C. (1998). "Shared understanding as a condition for team design." Automation in Construction, 7(2-3), 111-121.

Van de Ven, A. H., and Zahra, S. A. (2016). "Boundary Spanning, Boundary Objects, and Innovation." Managing Knowledge Integration Across Boundaries, OUP.

Van Der Walt, J. S., Buitendag, A. A., Zaaiman, J. J., and Van Vuuren, J. J. (2009). "Community living lab as a collaborative innovation environment." Issues in Informing Science and Information Technology, 6(1), 421-436.

Van Geenhuizen, M. (2019). “Applying an RRI filter in key learning on urban living labs' performance.” Sustainability, 11(14). 